\title{
Direito fundamental à educação: núcleo essencial e retrocesso em relação à PEC 241/2016 E À MP 746/2016
}

Fundamental right to education: essential core and kickback regarding PEC 241/2016 AND MP 746/2016

José Henrique de Goes Professor de Direito Constitucional do Curso de Graduação em Direito das Faculdades Secal (Ponta Grossa-PR). Advogado. Mestrando em Ciências Sociais Aplicadas pela Universidade Estadual de Ponta Grossa-UEPG. Especialista em Direito Público pela Escola da Magistratura Federal do Paraná-ESMAFE/PR/UniBrasil. Bacharel em Direito pela Universidade Estadual de Ponta Grossa-UEPG henriquedegoes@hotmail.com

Resumo O trabalho pretende demonstrar a existência de vedação constitucional de natureza principiológica à modificação de normas constitucionais e infraconstitucionais para o direito à educação. Primeiramente, analisa o direito à educação, conforme previsto na Constituição Federal de 1988-CF/88 e na Lei de Diretrizes e Bases da Educação-LDB, quanto aos seus objetivos e à progressividade de sua garantia. Examina a vedação ao retrocesso social por meio do núcleo essencial. Por fim, analisa as disposições da Proposta de Emenda à Constituição número 241/2016-PEC 241 e da Medida Provisória número 746/2016 à luz do direito fundamental à educação e do princípio da vedação ao retrocesso. A pesquisa é bibliográfica e documental, a partir do método dedutivo. Palavras-chave: DiREITO FUndAMENTAL; À EDUCAÇÃo; VedAÇÃO AO RETROCESSO; PEC 241. MP 746. 
Abstract The paper intends to demonstrate the existence of a constitutional seal of a principiological nature to the modification of constitutional and constitutional norms for the right to education. First, it analyzes the right to education, as provided for in the Federal Constitution of 1988-CF/88 and in the Law of Guidelines and Bases of EducationLDB, regarding its objectives and the progressiveness of its guarantee. It analyzes the fence to social retrogression through the essential nucleus. Finally, it analyzes the provisions of the Proposed Amendment to Constitution $n^{\circ}$. 241/2016-PEC 241 and Provisional Measure $n^{\circ}$. $746 / 2016$ in light of the fundamental right to education and the principle of prohibition against retrocession. The research is bibliographical and documentary, from the deductive method.

Key-words: Fundamental right to education; Backward Sealing; PEC 241. MP 746.

\section{INTRODUÇÃO}

$\mathrm{O}$ direito fundamental à educação previsto na $\mathrm{CF} / 88$ e na $\mathrm{LDB}$ determina como objetivo da educação o fomento à cidadania e ao pleno desenvolvimento humano, e prevê o aumento progressivo da garantia de tal direito.

O princípio da vedação ao retrocesso social é implícito na referida Carta, utilizado para determinar critérios de limitação a modificações às normas de direitos fundamentais. O núcleo essencial dos direitos sociais é tido como base para tal análise, e, para alguns, é intangível.

As propostas legislativas que possibilitam a não oferta de disciplinas a todos (MP 746) e limitação abaixo do mínimo constitucional para despesas com a educação (PEC 241) desafiam interpretação acerca da constitucionalidade de suas previsões a partir da vedação ao retrocesso.

O objetivo do trabalho é demonstrar a existência de vedação constitucional, decorrente da vedação ao retrocesso, à modificação de normas relativas ao direito à educação.

$\mathrm{O}$ desenvolvimento se dá com a análise do direito fundamental à educação na $\mathrm{CF} / 88$ e na $\mathrm{LDB}$, especificamente quanto aos objetivos e 
determinação de garantia progressiva. Ainda, com a análise do princípio da vedação ao retrocesso a partir do núcleo essencial dos direitos fundamentais, a partir de doutrina nacional. Por fim, pretende utilizar o caso das modificações legislativas pretendidas na PEC 241 e na MP 746 para demonstrar a aplicação das categorias analisadas.

Portanto, partindo-se do direito à educação como delineado na $\mathrm{CF} / 88$ e na LDB, bem como do princípio da vedação ao retrocesso, identificando critérios de intangibilidade, demonstrando sua aplicação em caso, o método é dedutivo. A pesquisa, como se depreende, é documental e bibliográfica.

\section{Direito À eduCAÇÃo Na República Federativa DO BRASIL: CONCEPÇÃO NORMATIVA E INTERPRETAÇÃO teórica do Direito Fundamental Social}

A CF/88 advém de tradição de previsão de financiamento e gratuidade de ensino, cuja abrangência variou de acordo com as escolhas político-ideológicas que indicavam um tipo de política econômica e seus reflexos na educação.

José Afonso da Silva (DA SILVA apud MALISKA, 2007, p. 209) menciona que tal tradição remonta aos tempos imperiais, pois a Constituição de 1824, que, aliás, limita seu texto sobre a educação a esse princípio, dispôs ser "a Instrução primária [...] gratuita a todos os Cidadãos”. Conforme Dermeval Saviani (2007, p. 243), isso, na verdade, representava apenas um ideal, pois não existia um sistema público de educação, que tinha como mais próximo de realização uma disposição legal de 1827, para que se instaurasse escola de primeiras letras em todos os povoados, o que não produziu frutos, tendo em vista a transferência de responsabilidade do ensino primário e secundário às províncias, como estipulado no $\S 2^{\circ}$. do artigo 10 do Ato Adicional à Constituição do Império, de 1834.

Versou a Constituição de 1934 (BRASIL, 1934), a segunda republicana, um capítulo todo à educação e à cultura. Nela, a gratuidade é 
referente ao ensino primário, conforme alínea "a" do $\S$ único do artigo 150. Também previa a obrigatoriedade do ensino primário (alínea "a" do § único do artigo 150), a seleção de mérito (alínea "e" do § único do artigo 150), a estabilidade dos professores e remuneração condigna (alínea “f” do § único do artigo 150), liberdade de cátedra (artigo 155), provimento de cargos por concurso (artigo 158), cargos esses vitalícios (artigo 158, § $2^{\circ}$.), inamovíveis (artigo 158, § $2^{\circ}$.).

Os princípios foram relativizados pela Constituição de 1937 (BRASIL, 1937), que definiu, em seu artigo 129, que o ensino pré-vocacional e profissional era prioridade do Estado em matéria de educação, mas subsidiado pela iniciativa dos entes federados e dos particulares, das indústrias, que deveriam criar escolas de aprendizes para os filhos dos empregados, e a gratuidade prevista não excluía o dever de solidariedade dos menos para com os mais necessitados, sendo exigida daqueles uma contribuição mensal. O sistema não era integrado, tendo leis orgânicas que regularam, além do secundário e primário, os ensinos industrial, comercial e normal, complementados pela criação do SENAI e do SENAC, pois a educação profissional era a prioridade.

Já a Constituição de 1946 (BRASIL, 1946) retomou a sistemática da Constituição de 1934, e a de 1967 relativizou novamente o princípio da gratuidade, no inciso III do $\S 3^{\circ}$. do artigo 168, que dispôs: "sempre que possível, o Poder Público substituirá o regime de gratuidade pelo de concessão de bolsas de estudo, exigido posterior reembolso no caso de grau superior". E, além disso, não contemplou as disposições relativas à vinculação orçamentária e aos professores. Tudo mantido pela Constituição de 1969.

Na CF/88 (BRASIL, 1988), compete também à União (artigo 23, $\mathrm{V}$, da $\mathrm{CF} / 88$ ) proporcionar os meios de acesso à educação, direito de todos e dever, também, do Estado, e que visa ao pleno desenvolvimento da pessoa, seu preparo para o exercício da cidadania e sua qualificação para o trabalho (artigo 205, CF/88). Um dos princípios estabelecidos no artigo 206 da CF/88 é a igualdade de condições para o acesso e permanência na escola (inciso I), acompanhado pela gratuidade do ensino 
público (inciso IV), pela valorização dos profissionais da educação escolar (inciso V), e pela gestão democrática (inciso VI).

A universalização, aliás, constitui direito subjetivo público, o que garante que todas as instituições criadas pelo Estado sejam de acesso e permanência gratuitos.

A gratuidade entendida como prestação refere além do que já foi mencionado, pois trata de condições que o Estado deve dar aos educandos para que desempenhem bem as tarefas escolares. O artigo 208, VII, da $\mathrm{CF}$, determina o atendimento ao educando por programas suplementares de material didático-escolar, transporte, alimentação e assistência à saúde. E cabe, ainda, a colocação de José Afonso da Silva (DA SILVA apud MALISKA, 2001, p. 210) de que o ensino fundamental tem papel na garantia de gratuidade do ensino público superior, garantia essa de eficácia realizada pela qualidade, dizendo que "compete ao Poder Público, desde a pré-escola, ou até antes, proporcionar, aos alunos carentes, condições de igualização, para que possam concorrer com os abastados em igualdade de situação".

O primeiro princípio geral do ensino público é o da Igualdade de Condições para o Acesso e Permanência na Escola (inciso I do artigo 206 da CF). Igualdade como valor aliado ao de (oportunidade igual de) vida, no entender de Canotilho (CANOTILHO, 2004).

Trata-se do direito de escolha de escola, com igualdade de oportunidades para tal escolha. No Estado Social Democrático, não somente igualdade formal, mas, através da lei, esta como regulação diferenciada das situações desiguais, para que se constituam instrumentos de libertação (MALISKA, 2001, p. 171-172).

Importante trecho de citação da doutrina de Canotilho (2004):

Esta igualdade assume dois aspectos: (i) conexiona-se "com uma política de $<<$ justiça social $>>$ e com a concretização das imposições constitucionais tendentes à efetivação dos direitos econômicos, sociais e culturais"; (ii) $[. .$.$] "e como princípio sancionador da violação da$ igualdade por comportamentos omissivos (insconstitucionalidade por omissão)". 
O dever do Estado será garantido, conforme expressa previsão no artigo 208 da Carta, mediante a garantia de progressiva universalização do ensino médio gratuito (inciso II), acesso aos níveis mais elevados do ensino, da pesquisa e da criação artística, segundo a capacidade de cada um (inciso V), atendimento ao educando, em todas as etapas da educação básica, por meio de programas suplementares de material didático escolar, transporte, alimentação e assistência à saúde (inciso VII).

A CF/88 ainda é expressa em declarar o acesso ao ensino obrigatório e gratuito como direito público subjetivo (parágrafo primeiro do artigo 208), e que o não-oferecimento do ensino obrigatório pelo Poder Público, ou sua oferta irregular, importa responsabilidade da autoridade competente (parágrafo segundo).

Para tanto, estabelece o artigo 212 da CF que a União aplicará, anualmente, nunca menos de dezoito por cento da receita resultante de impostos na manutenção e desenvolvimento do ensino.

E, conforme o parágrafo terceiro do artigo 208, a distribuição dos recursos públicos assegurará prioridade ao atendimento das necessidades do ensino obrigatório, no que se refere à universalização, garantia de padrão de qualidade e equidade, nos termos do plano nacional de educação.

A LDB (BRASIL, 1996) trata o ensino fundamental em seu artigo 32 , obrigatório e gratuito na escola pública, tendo como objetivo a formação básica do cidadão mediante: o desenvolvimento da capacidade de aprender, por meio do pleno domínio da leitura, da escrita e do cálculo; a compreensão do ambiente natural e social, do sistema político, da tecnologia, das artes e dos valores sobre os quais se fundamenta a sociedade; o desenvolvimento da capacidade de aprendizagem, tendo em vista a aquisição de conhecimentos e habilidades e a formação de atitudes e valores; o fortalecimento dos vínculos de família, dos laços de solidariedade humana e de tolerância recíproca sobre os quais se assenta a vida social.

A Lei determina, em seu artigo 35, que o ensino médio, como etapa final da educação básica, deve ter como finalidades: a consolidação e o aprofundamento dos conhecimentos adquiridos no ensino fundamen- 
tal (inciso I), a preparação básica para o trabalho e a cidadania (inciso II), o aprimoramento do educando como pessoa humana, incluindo a formação ética e o desenvolvimento da autonomia intelectual e do pensamento crítico (inciso III).

$\mathrm{A}$ CF ainda relega à lei que estabeleça o plano nacional de educação, decenal, a articulação do sistema nacional para assegurar o desenvolvimento do ensino, por ações que conduzam à universalização do atendimento escolar (inciso I do artigo 214), à promoção humanística do país (inciso V), o estabelecimento de meta de aplicação de recursos públicos em educação como proporção do produto interno bruto (inciso VI).

Por sua vez, o Plano Nacional de Educação-PNE, estabelecido na lei 13.005/2014 para o decênio 2014-2024, contém anexo em que estabelece meta de ampliar o investimento público em educação pública de forma a atingir, no mínimo, o patamar de 7\% do Produto Interno Bruto-PIB do país no quinto ano de vigência da Lei e, no mínimo, o equivalente a $10 \%$ do PIB ao final do decênio.

Ainda, estabelece como metas estimular a diversificação curricular da educação de jovens e adultos, articulando a formação básica e a preparação para o mundo do trabalho e estabelecendo inter-relações entre teoria e prática, nos eixos da ciência, do trabalho, da tecnologia e da cultura e cidadania; universalizar o ensino fundamental de 9 anos para toda a população de 6 a 14 anos de idade e garantir que pelo menos $95 \%$ dos alunos concluam essa etapa na idade recomendada, até o último ano de vigência do PNE.

Portanto, o ensino público deve ofertar universalidade de vagas, de forma progressiva, garantindo formação adequada à cidadania, por meio de currículos que permitam articulação entre teoria e prática no eixo da cultura e da cidadania. Tais ações previstas no PNE estão em consonância com o objetivo constitucional relativo ao fomento da educação formal à cidadania. A universalização e a valorização da atividade docente, objetivos previstos em ambos os textos, deve se dar, conforme a previsão constitucional, com no mínimo $15 \%$ dos impostos anuais da União. E com aumento progressivo do investimento em relação ao PIB. 
O PNE foi construído a partir de participação democrática, que culminou em texto legal aprovado pelo Legislativo com a maior legitimidade possível por meio dos instrumentos de democracia comumente percebidos na experiência brasileira, como as consultas públicas.

A doutrina relaciona o direito à educação com a democracia social decorrente do Estado Democrático de Direito, que, nas palavras de Luiz Fernando Calil de Freitas:

\begin{abstract}
...se materializa em termos do dever de proteção aos direitos fundamentais, notadamente aos direitos a prestações positivas, justamente em razão de sua conotação cultural, social e econômica, no sentido de ser desenvolvida atividade econômica e social necessária e suficiente ao atingimento dos fins constitucionalmente estabelecidos (FREITAS, L. F. C. de, 2007, p. 216-217).
\end{abstract}

Os fins constitucionalmente estabelecidos para a República Federativa do Brasil incluem a Justiça Social (artigo $3^{\circ}$.) e, relativamente à educação, a preparação à cidadania, portanto, como supedâneo.

Quanto ao preparo para a cidadania, Hesse (HESSE apud MALISKA, 2001, p. 161) entende que:

\begin{abstract}
Em tudo, democracia é, segundo seu princípio fundamental, um assunto de cidadãos emancipados, informados, não de uma massa de ignorantes, apática, dirigida apenas por emoções e desejos irracionais que, por governantes bem intencionados ou mal intencionados, sobre a questão do seu próprio destino, é deixada na obscuridade.
\end{abstract}

Para Maliska (2001, p. 40), o direito à educação tem caráter de fundamento de legitimidade de qualquer sociedade. Citando Sarlet (SARLET apud MALISKA, A., 2001, p. 43), considera os direitos fundamentais, delimitados espacial e temporalmente, com caráter básico e fundamentador do sistema jurídico do Estado de Direito, como expresso em sua denominação. 
Conforme Maliska (2001), no Estado Social Democrático de Direito a compreensão do direito fundamental à educação revela-se condição para um Estado e sociedade ancorados no princípio democrático. Mas, se da concepção histórica dos direitos sociais extrai-se que o direito à educação é prestacional e exigido do Estado, tendo caráter público subjetivo, tem-se no desenvolvimento econômico condição para a sua realização.

Esse entendimento, no entanto, que parece de racionalidade financeira da educação, pode ser contestado com a teoria do desenvolvimento que contempla investimentos mínimos em educação, bem como, deve ser contraposto a teorias que limitam as limitações aos direitos sociais, como o princípio da vedação ao retrocesso, sob pena de se ter, na política de governo e na respectiva compreensão de política econômica, possibilidades de modificação das disposições normativas tendentes a retrocessos, subjugando o fim da ordem econômica, Justiça Social (artigo 170 da CF), ao objeto de sua regulação, o mercado.

Maliska (2001) entende que o Estado neoliberal intervém na ordem econômica a fim de garantir o funcionamento do sistema, mas não se pode admitir um Estado que intervém somente para garantir ordem e segurança, pois isso não seria compatível com a ideia de Estado radicalmente democrático, que os indivíduos integram. Daí uma transformação do Estado Neoliberal intervencionista para o Social Democrático de Direito, um momento de redefinição do papel estatal, o que dá importância às políticas públicas que viabilizam o estado gerencial. Não se pode, no entanto, excluir o compromisso com os direitos sociais, que em realidade não têm ligação direta com o modelo econômico.

$\mathrm{O}$ autor refere que o próprio Estado Social Democrático de Direito caracteriza-se pelo controle da sociedade civil organizada, para proteger as instituições democráticas de ameaças.

Nesse sentido, as ideias do professor Konrad Hesse (HESSE apud MALISKA, A., 2001, p. 56-57), que refletem a ligação de dependência entre os direitos individuais e os sociais, uma vez que a democracia não seria conceito definido senão nas Constituições e que mesmo nestas, está aberto à criação popular, porém impossível de ser sequer pensada 
se aos cidadãos não são possibilitadas condições mínimas para que haja educação, emancipação.

A constatação de que a cidadania necessita da educação está, por exemplo, para Gina Pompeu (2005, p. 19), na constatação inversa de que o distanciamento da população do Estado se dá em razão da falta de educação.

Para Maliska (2001, p. 57), os direitos fundamentais, porque integram, com a forma de Estado, sistema de governo e organização do poder, a essência do Estado, condicionam formalmente a validade da ordem jurídica, e também materialmente. Tal controle de constitucionalidade se refere inclusive à atuação privada, pois a Constituição trará também aspectos da vida comunitária que não seriam da ordem estatal, já que agora todos devem vincular-se efetivamente ao pacto social.

No entender de Edimilsom Pereira de Farias (DE FARIAS apud MALISKA, 2001), os direitos sociais especificam e densificam o princípio da dignidade da pessoa humana, que é aberto, respaldando o surgimento de novos direitos implícitos na Constituição em decorrência de princípios por ela adotados. Assim, a dignidade da pessoa humana seria o critério interpretativo do ordenamento constitucional.

Não se trata aqui, porém, de discutir a respeito da criação de novos direitos fundamentais além dos constantes do rol do título II da CF. Mas de demonstrar que a educação não pode ser entendida, enquanto direito, isolada dos princípios e objetivos do Estado, mas sim interpretada de acordo com eles. E, portanto, suas políticas públicas não podem ser concebidas a partir de um conceito de qualidade, por exemplo, que é elemento do direito previsto na Constituição, alheio à intervenção democrática e à promoção de Justiça Social, cujo princípio, no Brasil, constitui objetivo da ordem social e econômica.

Se a CF constitui sistema de estrutura dialógica, como já citado, aberta, porque ancorada na disponibilidade e capacidade de aprendizagem das normas constitucionais para captarem a mudança da realidade e estarem acessíveis às concepções cambiantes da verdade e da justiça, não se pode admitir políticas públicas que intentam uma qualidade somente técnica, e assim impedem o desenvolvimento de cidadãos para que promovam, por meio da cidadania, Justiça Social. 
Importante a interpretação de que os sociais sejam garantidos de acordo com os demais princípios constitucionais. Pois, se o direito à educação é fundamental, a ordem social é também base do Estado, e esta visa à Justiça Social. Decorrente daí que a educação capacite o indivíduo ao exercício pleno de suas possibilidades, inclusive para a cidadania.

Os direitos fundamentais são subjetivos individuais, mas, por serem decisões valorativas de natureza jurídico-objetiva constitucionais, no dizer de Vieira de Andrade, se dá outra atribuição a eles:

...o valor da solidariedade, isto é, da responsabilidade comunitária dos indivíduos: descobre-se a dimensão participativa, incluindo no âmbito dos direitos as atuações individuais de caráter político; acentua-se a dimensão sócia (VIEIRA DE ANDRADE apud MALISKA, A. O Direito à Educação e a Constituição. Porto Alegre: Sergio Antonio Fabris Editor, 2001, p. 99).

Para Canotilho (2004), existem direitos fundamentais que têm função objetiva e subjetiva, pois têm importância para o indivíduo (interesses, ideias, desenvolvimento como pessoa) como para a coletividade, sendo um valor geral, de importância para a vida comunitária.

O foco está no direito à educação enquanto interesse individual e comunitário, usando novamente as palavras de Canotilho, e a combinação dos interesses só é possível na coerência da prática educativa com o princípio da justiça social brasileiro. Ou seja, trata-se de estudar o tipo de qualidade a que o ensino fundamental público se presta, em comparação com a qualidade a que se obrigou a atividade legislativa e executiva pelo texto constitucional. É, portanto, com esse enfoque, que se busca perceber a solidez constitucional do direito em análise.

O artigo 205 da CF objetiva a educação para o trabalho, e este é primado da ordem social que visa à Justiça Social, segundo os artigos 193 e 170.

Seguindo a classificação de Jellinek dos status como situações dos indivíduos diante do Estado, existe o passivo, situação de subordinação do indivíduo aos poderes estatais; o negativo, em que está a esfera de 
liberdade intocável pelo Estado; o positivo, em que o indivíduo pode fazer uso das instituições estatais, podendo exigir ações do Estado; e o ativo, em que há cidadania ativa, ou seja, participação ativa da vontade estatal (JELLINEK apud MALISKA, 2001, p. 139).

Segundo Canotilho (2004), o gênero direito de prestações engloba os direitos de acesso e utilização de prestações estatais e os direitos de participação na organização e procedimento de realização.

Para Haberle (apud MALISKA, 2001), no Estado Constitucional Democrático, a legitimação é colocada sob a perspectiva democrática. E por isso, da democratização da democracia. Utilizando praticamente as palavras de Haberle: a democracia não tem que ver só com a participação pelo voto, mas com a controvérsia sobre alternativas, possibilidades, necessidades da realidade e "concerto" científico a respeito de questões constitucionais, nas quais não existe dirigente. Isso tem a ver com a construção de uma nova sociedade, em que a formação de uma vida política se dá pela pluralidade de ideias, e em que os direitos fundamentais são presentes e atuantes pela força de seus titulares.

Para Maliska (2001, p. 145), o Estado, que cria instituições que prestam direitos sociais, não pode dirigi-las contra a prestação prevista para elas, o que seria um retrocesso social. E somente as leis que refletem o desenvolvimento constitucional, e não somente uma interpretação legal dada pela maioria parlamentar ou pelo governo, têm a proteção da proibição de retrocesso.

Nesse sentido, permite-se rever políticas públicas e uma lei de diretrizes e bases se elas refletem somente um caráter de qualidade entendida como preparação técnica exclusivamente.

E aí, a Constituição é dirigente dos direitos sociais, segundo Canotilho (2004), que também conceitua os direitos sociais como vinculantes, de densidade normativa reduzida, mas subjetivos, podendo dar ensejo às ações de inconstitucionalidade por omissão, e também um direito originário a prestações, pois a garantia constitucional reconhece o dever do Estado da criação dos pressupostos materiais ao exercício.

$\mathrm{O}$ direito à educação é tipicamente de prestação em sentido estrito (fático), tendo a Constituição o assumido como dever estatal. José 
Afonso da Silva (apud MALISKA, 2001) considera sua não prestação um desrespeito à norma, pois tem qualidade de direito subjetivo público no ensino obrigatório.

A concepção da educação enquanto direito social que consolida a distribuição democrática da materialidade produzida socialmente está baseada no Estado Democrático de Direito de modelo social. No Estado brasileiro, a distribuição dos bens sociais a partir dos direitos sociais reconhecidos é obrigatória, ante à determinação da Justiça Social enquanto fim.

\title{
3 As LiMitaÇões À GARANTIA EDUCACIONAL PELA POLÍTICA OR- ÇAMENTÁRIA: PEC 241, MP 746/2016 À LUZ dO PRINCÍPIO DA VEDAÇÃO AO RETROCESSO
}

A cláusula de proibição de retrocesso está vinculada aos direitos fundamentais sociais, cujas normas, estabelecidas via prestações em políticas públicas por desenvolvimento legislativo, não podem sofrer supressões sem compensação (DERBLI, 2007, p. 133ss.). Como princípio implícito na $\mathrm{CF}$, decorrente da previsão de Estado Democrático de Direito, com modelo social estabelecido por meio de direitos sociais, objetivando a Justiça Social, está estabelecido.

O princípio estabelece que:

\begin{abstract}
...o núcleo essencial dos direitos sociais já realizado e efetivado através de medidas legislativas deve considerar-se constitucionalmente garantido, sendo inconstitucionais quaisquer medidas estaduais que, sem a criação de outros esquemas alternativos ou compensatórios, se traduzam, na prática, numa "anulação", "revogação" ou "aniquilação" pura e simples desse núcleo essencial (CANOTILHO, 1997, 339).
\end{abstract}

As ideias de dignidade da pessoa humana e de mínimo existencial igualmente encontram-se diretamente vinculadas ao princípio da proibição de retrocesso social, conforme adverte Sarlet (2012). 
A teoria da proteção do núcleo essencial concentra-se em que as restrições a direitos fundamentais não podem atingir sua essência, esvaziando o seu conteúdo. Tal núcleo seria absoluto e compreendido objetiva e subjetivamente (SGARBOSSA, 2009, p. 194).

Para Luiz Fernando Sgarbossa (2009), o núcleo essencial dos direitos sociais tem critérios ligados à atividade prestacional do Estado. Assim, a omissão implicaria inconstitucionalidade, assim comoas ações por meio das quais o Estado não se desincumbe de promover os direitos sociais.

A análise da violação ou adequação das medidas previstas na PEC 241 (artigo $1^{\circ}$.) e na MP 746 depende, portanto, da verificação de tais critérios.

A proposta de Emenda determina que os gastos públicos com educação sejam limitados, em determinado ano, pelo valor dos gastos no ano anterior acrescido da inflação. E a Medida Provisória faculta a oferta, de forma eletiva, de disciplinas como história, , filosofia, sociologia.

Tomam-se três pontos de análise: a progressividade da oferta como parte do núcleo essencial do direito à educação; o ensino das disciplinas de história e sociologia como parte do núcleo essencial do direito à educação; o conteúdo do direito à educação como determinante da possibilidade de sua inserção na dimensão social da cidadania.

A previsão do inciso II do artigo 107, acrescido ao ADCT pela EC 95 de 2016, de limitar os gastos com educação e outros gastos para a manutenção dos serviços públicos que correspondem a direitos sociais ao valor do limite referente ao exercício anterior corrigido por índice de inflação, afronta ao núcleo essencial do direito à educação se se constitui em impossibilidade de manutenção de vagas, uma vez que a impossibilidade de matrícula por inexistência de vaga exclui o gozo do direito à educação por pretenso aluno.

Fere-se a progressividade da oferta em direção à gratuidade e universalidade prevista para o Ensino Médio a nível constitucional (artigo 208, II).

De acordo com o Censo Escolar (BRASIL, 2015), três milhões de pessoas entre 4 e 17 anos de idade estão fora da escola, o déficit na 
oferta para crianças de 4 e 5 anos de idade era, em 2010, de cerca de 41 mil vagas. No Rio de Janeiro, segunda cidade mais populosa do país, faltavam 17,9 mil vagas nessa faixa etária em 2011. Já para o ensino médio, a capital paulista precisaria criar 74 mil vagas, e a fluminense, 37 mil vagas. Portanto, haverá um acréscimo de demanda, a ser suprido nos próximos anos.

Porém, a necessidade de aumento do orçamento da educação desafia o limite aos gastos atuais, indicando a inexistência da possibilidade de criação de vagas sem aumento do sistema.

A conclusão é de que o direito fundamental à educação daqueles que não têm acesso possível, sem perspectiva de aumento, indicado no PNE como necessário, impossibilita ao Estado se desincumbir do seu ônus relativamente à universalização.

Quanto às disposições da MP em comento, cabe a indagação sobre a possibilidade de garantir a formação mínima para a cidadania considerando-se obrigatórias apenas as disciplinas de português e matemática, uma vez que, conforme José Murilo de Carvalho (2002), uma das maiores dificuldades em relação à garantia de cidadania no Brasil é justamente a falta de educação em Direitos Humanos, e a falta de compreensão de fenômenos históricos, políticos e sociais.

Haverá a possibilidade de o aluno escolher receber, além de conteúdos de português e matemática, apenas ensino técnico, destinado à formação técnica profissional, conforme o parágrafo nono do artigo 36 História, filosofia e sociologia se tornam opcionais.

Se a educação se destina à formação para a cidadania, sendo também constituinte do rol de direitos fundamentais que compõem o aspecto social da cidadania, o ensino de disciplina como história, que visa à compreensão dos fenômenos sociais que contribuíram para a formação social e política das sociedades, e se a compreensão de tais processos se encontra no conteúdo do direito à educação conforme previsto no ordenamento para o Ensino Médio, equivale a retrocesso sua retirada do currículo aplicável ao estudante que optou por formação técnica.

No ordenamento jurídico brasileiro, a previsão era da obrigatoriedade das disciplinas nos três anos do curso médio proporcionava que os 
objetivos específicos para a etapa de formação, previstos nos incisos II e III do artigo 35 (formação para cidadania e aprimoramento do pensamento crítico).

Assim, o núcleo essencial do direito inclui tais finalidades, uma vez que se trata de seu conteúdo. Não existe o direito à educação, como previsto nos artigos 205 da CF, 35, II e III, da LDB, sem formação para a cidadania, que inclui fomento ao pensamento crítico e ao conhecimento dos processos históricos de formação social. Isso se detona, literalmente, do parágrafo primeiro do artigo 26, que refere à educação básica como um todo, e portanto tamém ao ensino médio: “Os currículos a que se refere o caput devem abranger, obrigatoriamente, o estudo da língua portuguesa e da matemática, o conhecimento do mundo físico e natural e da realidade social e política, especialmente do Brasil".

A disciplina de história e a disciplina de sociologia, no Ensino Médio, são as responsáveis por fomentar ao conhecimento da realidade social e política.

Sobre o aspecto da garantia da educação como parte do elemento social da cidadania, Thomas Humphrey Marshall, social democrata, no clássico "Cidadania, Classe Social e Status", classifica três elementos da cidadania, que, na modernidade, seria identificada pelo gozo de tais partes, as quais comportariam determinados direitos fundamentais. Os elementos seriam civil, político, social. $\mathrm{O}$ rol dos direitos previstos no elemento social inclui educação.

$\mathrm{O}$ autor menciona que o economista Alfred Marshall, autor clássico do liberalismo inglês, menciona que, no caso da educação, o Estado deveria usar a coerção caso necessitasse, para realizar seus ideais, indicando que, embora não entenda que os direitos sociais, que visam à redução de desigualdades, devam ensejar a atuação do Estado, neste caso isso se faria necessário, para que fosse concedido a todo indivíduo o mínimo de participação no produto civilizatório da sociedade na qual se insere. Em relação às diferenças econômicas, considerava não haver erro, mas condenava a desigualdade qualitativa entre o cavalheiro (civilizado) e que não o era. Tratava-se de exigências para a consideração do status de cidadão. (MARSHALL, 1967, p. 61) 
Para Thomas Humphrey Marshall, o sistema de cidadania inglês no século XX era socialista, no sentido de que o mercado tinha limites. Ao questionar se haveria limites à igualdade social (não no sentido de custos, os quais não impediriam, com o progresso, no entender de Alfred Marshall), entende que a tendência moderna de cidadania é inevitável e remete a uma evolução de seu conteúdo, desde o século XVIII. (MARSHALL, P. 63)

As primeiras leis fabris, na mesma linha, não deram direitos sociais como limitação de jornada, aos cidadãos por excelência, os homens, mas a mulheres e crianças. No fim do século XIX, o argumento se tornou obsoleto e o código industrial se tornou pilar dos direitos sociais. (MARSHALL, 1967, P. 73)

No fim do século XIX, a educação primária era obrigatória, combinando um dever público de exercer tal direito. Cada vez mais se necessitava de eleitores educados e trabalhadores qualificados, bem como de técnicos para a produção científica. Assim, o dever de auto aperfeiçoamento e de auto civilização é social. A civilização dependia de uma herança nacional, estabelecendo-se bases para o restabelecimento dos direitos sociais da cidadania no século XX. (MARSHALL, 1967, P. 74)

No fim do século XIX e início do século XX, uma reforma no sistema de ensino se fez a partir de uma lei que determinou maiores admissões, por mais critérios de excelência, e com mais possibilidades de habilidades a serem aprendidas, o que foi recebido com tom entusiástico. (MARSHALL, 1967, P. 75)

No século XIX, houve mudanças significativas no princípio igualitário, como avanços nos direitos sociais. Houve aumento de rendas nominais desigualmente distribuído pelas classes, modificando a distância econômica que separava essas classes entre si, diminuindo a distância entre especializados e não especializados, bem como entre estes e os trabalhadores não manuais. $\mathrm{O}$ aumento das pequenas poupanças diminuiu as distinções de classe entre capitalista e proletário sem bens. (MARSHALL, 1967, 89)

Cresceu a luta por um direito universal a um renda real não proporcional ao valor de mercado do reivindicador. O objetivo dos direitos 
sociais é a redução das diferenças de classe, mas adquiriu novo sentido: não mais tentar eliminar o ônus da pobreza nos níveis mais baixos, mas ação modificativa do padrão total da desigualdade social. A mudança era na superestrutura. (MARSHALL, 1967, P. 89)

O princípio mais comum para avaliar a questão do que será garantido é o mínimo de certos bens e serviços, essenciais, como assistência médica, moradia, educação, renda nominal mínima, a ser gasto em bens e serviços essenciais. O grau de igualação depende de quatro fatores: se o benefício é oferecido a todos ou a uma classe limitada, se assume a forma de pagamento em dinheiro ou prestação de serviço; se é alto ou baixo; como se levanta dinheiro para pagá-lo. Os benefícios em dinheiro sujeitos ao teste dos meios e limites de renda teve efeito simples. A igualação teve efeito estigmatizante. (MARSHALL, 1967, p. 93)

A ampliação dos serviços pode exercer um efeito sobre os aspectos qualitativos da diferenciação social. As antigas escolas públicas primárias, embora abertas a todos, era utilizadas por uma classe social para a qual não havia outra educação disponível. Havia o estigma do aluno de escola pública. Na década de 1960, a segregação ainda existia, mas a educação subsequente, à disposição de todos, fazia com que um reajustamento fosse possível.

A intenção é a expansão dos serviços, de maneira que todos o tenham e que, o que o rico tiver a mais seja apenas o luxo. Pois o serviço oferecido, e não o que se compra, torna-se a norma do bem-estar social. Neste sentido:

Um mínimo de direitos legalmente reconhecidos pode ser concedido, mas o que interessa ao cidadão é a superestrutura das expectativas legítimas. Pode ser razoavelmente fácil fazer com que toda criança, até cera idade, passe um certo número de horas na escola. É muito mais difícil satisfazer as expectativas de que a educação deveria estar a cargo de professores treinados e ser dada em classes de tamanho moderado. 
O autor defendia que o ritmo de progresso depende da magnitude dos recursos nacionais e da distribuição destes dentre as reivindicações competitivas. $\mathrm{O}$ Estado não pode prever qual será o custo do cumprimento de suas obrigações, pois à medida que o padrão que se espera aumenta, as obrigações se tornam mais pesadas. Assim, os direitos individuais devem estar subordinados aos planos nacionais (pp. 95-97)

Um exemplo de como os direitos sociais estariam criando desigualdade social estaria na educação. Inicialmente, educação pública na Inglarerra era parte de direitos mínimos e iguais. A ele correspondia uma obrigação, da criança, de se desenvolver, de acordo com a oportunidade, porque a sociedade reconheceu que necessitava de uma população educada. Acusa-se o século XIX de encarar a educação primária como meio de propiciar aos empregadores capitalistas trabalhadores mais aptos e a educação superior meramente como instrumento de umento do poder da nação na competição com rivais industriais. (MARSHALL, 1967, P. 98)

Numa segunda fase da educação na Inglaterra, em 1902 inaugurada, tinha a escada educacional como parte importante mas diminuta do sistema. Mas o equilíbrio entre direitos coletivos e individuais permaneceu o mesmo. O Estado decidia quanto podia dispor para aplicar em educação superior e secundária gratuita, e os estudantes competiam pelo limitado número de vagas. Não havia crença no sentido de que todos que poderiam ter benefícios de uma educação mais avançada a obteriam. Não havia o reconhecimento de um direito natural absoluto a ser educado de acordo com a capacidade de cada um. (MARSHALL, 1967, P. 99)

No terceiro período, em 1944, os direitos individuais receberam, ostensivamente, prioridade. A competição devia ser substituída pela seleção para as vagas, com distribuição em lugares apropriados, suficientes em número, para todos, ao menos em nível secundário. (MARSHALL, 1967, P. 99)

Na Lei de 1944, há passagem que afirma que o número de escolas não será considerado adequado a não ser que se propicie a todos oportunidades para educação, com tal variedade de instrução 
e treinamento quanto possa ser desejável em vista de suas aptidões, habilidades e idades diferentes. (MARSHALL, 1967, P. 100)

Esclarecedor o trecho do autor:

\begin{abstract}
Se fosse possível para o sistema educacional tratar o estudante inteiramente como um fim em si mesmo e encarar a educação como um meio de lhe dar algo cujo valor poderia aproveitar ao máximo, qualquer que fosse sua posição na vida profissional, então talvez fosse possível moldar o plano educacional numa forma determinada pelas necessidades individuais, a despeito de quaisquer outras considerações. Mas, como sabemos, a educação atualmente se encontra intimamente ligada à ocupação e um dos benefícios, pelo menos que o estudante espera dela é a qualificação para ocupar uma posição num nível apropriado. [...]. A proporção entre escolas primárias, técnicas e secundárias não pode ser determinada com precisão sem se fazer referência à proporção entre empregos de níveos correspondentes. (MARSHALL, 1967, P. 101)
\end{abstract}

Perceptível que a racionalidade da pretensa submissão dos direitos sociais à política financeira e econômica, presente nas concepções do autor em comento é compatível com a medida de redução dos gastos com educação em nome da hipotética necessidade de economia específica no campo dos direitos sociais.

Esta tendência política liberal não é compatível com a solução adotada na CF de 1988, que prevê a progressividade da oferta de ensino básico, até a universalização, bem como percentual mínimo de gastos do orçamento com os direitos sociais. Por outro lado, fica evidente que as idéias do autor são compatíveis com a política governamental inserida, como alteração na política de Estado, por meio da EC 95.

Mas também é perceptível que o fundamento inicial do autor é de que, no caso da educação, sua instrumentalidade, enquanto meio de formar o cidadão para o mercado de trabalho, é que determina a previsão de conteúdos aquém daqueles necessários à contemplação de todas as 
possibilidades do educando. Para este último objetivo, seria necessária a formação que capacite à compreensão de processos históricos, sociais, para todos os estudantes.

A CF de 1988 prevê que a educação forme à cidadania, e a LDB, que forme para o desenvolvimento do indivíduo em todas as suas potencialidades, inclusive para o pensamento crítico.

Fica evidente que não é o que se observa na política de governo que acaba por alterar o conteúdo do direito à educação ao retirar do currículo obrigatório as matérias que objetivam a tal formação.

\section{CONSIDERAÇões FINAIS}

O problema apontado por Freire (1996, p. 130) continua atual, pois a política pública de educação, quanto ao financiamento, revela aquela racionalidade financeira da educação uma falta do dever ser de uma ética a serviço do ser humano e não do lucro das minorias dominantes. Ou seja, exclui-se o pensar de uma política pelo desenvolvimento humano com o econômico.

No caso da retirada da obrigatoriedade de disciplinas que objetivam ao desenvolvimento do raciocínio crítico, por meio do conhecimento da sociedade, e, portanto, ao exercício da democracia e da cidadania, tal racionalidade fica evidenciada, uma vez que se privilegiam os conhecimentos tidos como necessários tão somente para o mercado de trabalho, com ênfase nas disciplinas de cunho técnico.

Em termos relativos à teoria constitucional, importa verificar que, se a diminuição dos gastos importa em diminuição ou estagnação das vagas- contrariamente à progressividade prevista em nível constitucional, e, se a possibilidade de não oferta de disciplinas possibilita a deficiência na compreensão de processos sociais, como o político, essencialmente históricos, previstos como conteúdo do direito à educação, dada a previsão de preparação ao pensamento crítico e à compreensão da realidade social e política, não haverá cumprimento da incumbência estatal relativa ao direito à educação, e, portanto, haverá retrocesso so- 
cial, não permitido pelo princípio implícito na $\mathrm{CF} / 88$, em decorrência dos princípios, fundamentos e objetivos da República.

A reforma do Ensino Médio, feita por Medida Provisória, sem debates característicos do exercício de participação democrática na formação de leis, refere a uma alteração de política de Estado, como no caso da educação, por meio de política de governo.

Como se inferiu a respeito da teoria de Marshall, a submissão de direitos sociais à racionalidade financeira e econômica é coerente com uma política de governo liberal, mas não com a política de Estado relativa à educação na CF de 1988. E a instrumentalização da educação para o mercado de trabalho, em cargos técnicos, indica incompatibilidade com os propósitos de formação para a cidadania, o pensamento crítico e o conhecimento da realidade social e política, previstos para a educação como direito fundamental na CF.

Assim, além as medidas de congelamento nos gastos com a educação e de retirada da parte obrigatória do currículo do Ensino Médio das matérias que fomentam à compreensão da realidade social e ao pensamento crítico ferem o núcleo essencial do direito à educação, sendo assim proibidas pela vedação ao retrocesso, o que as torna inconstitucionais.

Sua realização sem utilização dos mecanismos democráticos de debate público torna a alteração da política de Estado pela política de governo incompatíveis com o tipo de legitimidade política dos governos em democracias republicanas.

\section{REFERÊNCIAS}

BRASIL. Constituição da República dos Estados Unidos do Brasil, 16 de julho de 1934. Consulta em: 27 out. 2016. Disponível em: <http://www.planalto.gov.br/ccivil_03/Constituicao/Constituicao34.htm>

BRASIL. Constituição da República dos Estados Unidos do Brasil, 10 de novembro de 1937. Consulta em: 27 out. 2016. Disponível em: <https://www. planalto.gov.br/ccivil_03/Constituicao/Constituicao37.htm> 
BRASIL. Constituição dos Estados Unidos do Brasil, 18 de setembro de 1946. Consulta em: 27 out. 2016. Disponível em: <https://www.planalto.gov. br/ccivil_03/Constituicao/Constituicao46.htm>.

BRASIL. Constituição da República Federativa do Brasil, 5 de outubro de 1988. Consulta em: 27 out. 2016. Disponível em: <http://www.planalto.gov.br/ ccivil_03/constituicao/constituicaocompilado.htm $>$.

BRASIL. MEDIDA PROVISÓRIA 746, 22 de setembro de 2016. Consulta em: 22 set. 2016. Disponível em: < http:/www.planalto.gov.br/ccivil_03/ ato2015-2018/2016/Mpv/mpv746.htm>

BRASIL. Instituto Nacional de Geografia e Estatística. Notícia. Disponível em: <http://www.ibge.gov.br/home/presidencia/noticias/noticia_visualiza. php?id_noticia=1330\&id_pagina=1>. Consulta em: 22 set. 2009.

BRASIL. Instituto Nacional de Estudos e Pesquisas Educacionais Anísio Teixeira. Censo Escolar. Consulta em: 27 out. 2016. Disponível em: <http://portal.inep.gov.br/basica-censo-escolar-sinopse-sinopse>

BRASIL. Ministério da Educação. Notícia. Disponível em: <http://portal. mec.gov.br/redecomunicadores/index.php?option $=$ com_docman $\&$ task $=\mathrm{doc}$ details\&gid=199\&Itemid=238> . Consulta em: 22 set. 2009.

BRASIL. Lei 9.394, de 20 de dezembro de 1996. Estabelece as diretrizes e Bases da Educação. Consulta em: 27 out. 2016. Disponível em: <https://www. planalto.gov.br/ccivil_03/Leis/L9394.htm>

CANOTILHO, José Joaquim Gomes. Estudos sobre Direitos Fundamentais. Coimbra: Almedina, 2004.

CANOTILHO, José Joaquim Gomes. Tratado de Direito Internacional dos Direitos Humanos, vol. I. Porto Alegre: Sérgio Antonio Fabris Editor, 1997.

CARVALHO, José Murilo de. Cidadania no Brasil. O longo Caminho, 3. ed. Rio de Janeiro: Civilização Brasileira, 2002.

DERBLI, Felipe. O Princípio da Proibição de Retrocesso Social na Constituição de 1988. Rio de Janeiro: Renovar, 2007.

FREIRE, P. Pedagogia da autonomia: saberes necessários à prática educativa. São Paulo: Paz e Terra, 1996 (Coleção Leitura). 
FREITAS, Luiz Fernando Calil de. Direitos Fundamentais: limites e restrições. Porto Alegre: Livraria do Advogado, 2007.

MALISKA, M. A. O Direito à Educação e a Constituição. Porto Alegre: Sergio Antonio Fabris Editor, 2001.

MARSHALL, T. H. Cidadania, classe social e status. Rio de Janeiro: Zahar Editores, 1967.

POMPEU, Gina V. M. Direito à Educação: controle social e exigibilidade judicial. Rio-São Paulo-Fortaleza: ABC Editora, 2005.

SARLET, Ingo W. A eficácia dos Direitos Fundamentais: uma teoria geral dos direitos fundamentais na perspectiva constitucional. 11 ed. rev. e atual. Porto Alegre: Livraria do Advogado, 2012.

SAVIANI, Dermaval. Educação: do senso comum à consciência filosófica. Campinas, SP: Autores Associados, 2007, 17 ed. rev.

SGARBOSSA, L. F. Do Estado-Providência ao Mercado-Providência: Direitos sob a "reserva do possível" em tempos de globalização neoliberal. Dissertação de Mestrado. UFPR. 2009.

Submetido em: 23-02-2017

Aceito em: 30-03-2017 